\title{
Structural and physical properties of $\mathrm{Sm}^{3+}$ doped magnesium zinc sulfophosphate glass
}

\author{
F AHMADI ${ }^{1, *}$, R HUSSIN ${ }^{1}$ and S K GHOSHAL ${ }^{2}$ \\ ${ }^{1}$ Phosphor Research Group, Department of Physics, Faculty of Science, Universiti Teknologi Malaysia, 81310 Skudai, \\ Malaysia \\ ${ }^{2}$ Advanced Optical Materials Research Group, Department of Physics, Faculty of Science, Universiti Teknologi Malaysia, \\ 81310 Skudai, Malaysia \\ *Author for correspondence (ahmadi.fahimeh25@yahoo.com)
}

MS received 30 June 2016; accepted 30 January 2017; published online 22 September 2017

\begin{abstract}
Samarium $\left(\mathrm{Sm}^{3+}\right)$ doped magnesium zinc sulfophosphate glass system of composition $(60-x) \mathrm{P}_{2} \mathrm{O}_{5}-20 \mathrm{MgO}_{-}$ $20 \mathrm{ZnSO}_{4}-x \mathrm{Sm}_{2} \mathrm{O}_{3}(x=0.0,0.5,1.0,1.5$ and $2.0 \mathrm{~mol} \%)$ were synthesized using melt-quenching technique. The structure and physical properties of prepared glass samples were characterized. The X-ray diffraction pattern verified their amorphous nature. The physical properties such as density, refractive index, molar volume, rare earth ion concentration, etc. were calculated. The decrease in the optical bandgap energy with increasing $\mathrm{Sm}_{2} \mathrm{O}_{3}$ contents was attributed to the alteration in the glass network structures. Fourier transformed infrared spectra and Raman analyses manifested the depolymerization of $\mathrm{ZnSO}_{4}$ in the phosphate host matrix. The present findings may be beneficial for the advancement of functional glasses.
\end{abstract}

Keywords. Sulfophosphate glass; samarium; bandgap energy; Raman spectra; FTIR.

\section{Introduction}

Among oxide glasses, phosphate glasses possess several advantages over the conventional silicate and borate glasses. Attractive features such as high transparency, low melting point, high thermal stability, high gain density, excessive solubility of REIs, low refractive index and dispersion make phosphate glasses useful for many applications $[1,2]$. Besides, these oxide glasses have some disadvantages including weak chemical stability, high reactivity with water, powerful devitrification tendency and the requirement of difficult preparation conditions. In this regard, sulfophosphate glasses are presented to surmount these problems [3].

Low-melting sulfophosphate glasses were introduced for the first time by Mamoshin and co-workers in the 1980s [4-6]. The Fourier transformed infrared (FTIR) spectra of the $\mathrm{Na}_{2} \mathrm{SO}_{4}-\mathrm{NaPO}_{3}$ glass revealed the formation of separate sulfur-oxygen network in the sulfate groups, which are unbound to polyphosphate chains [6]. The possibility of the formation of a mixed sulfate phosphate has been approved by the NMR spectroscopy of $\mathrm{Li}_{2} \mathrm{SO}_{4}-\mathrm{Li}_{2} \mathrm{O}-\mathrm{P}_{2} \mathrm{O}_{5}$ and $\mathrm{Na}_{2} \mathrm{SO}_{4}-\mathrm{P}_{2} \mathrm{O}_{5}-\mathrm{H}_{2} \mathrm{O}$ glass systems [7,8]. The IR spectra of the $\mathrm{Li}_{2} \mathrm{SO}_{4}-\mathrm{LiPO}_{3}$ glass system demonstrated that the sulfate ions can be incorporated into the polyphosphate structural fragments to form the mixed sulfate phosphate network [9]. Sokolov et al [10] investigated the IR spectra of $\mathrm{Na}_{2} \mathrm{O}-\mathrm{Na}_{2} \mathrm{SO}_{4}-\mathrm{P}_{2} \mathrm{O}_{5}$ glass systems in which the observed band, around $620 \mathrm{~cm}^{-1}$, is assigned to the presence of
$\mathrm{SO}_{4}^{2-}$ in the glass network. Furthermore, the appearance of bands at 1170, 1130 and $640 \mathrm{~cm}^{-1}$ are attributed to the stretching and bending vibrations of $\mathrm{S}-\mathrm{O}$ of sulfate structural fragments, indicating the formation of sulfate phosphate structure. The complete absence of the absorption band at around $750 \mathrm{~cm}^{-1}$ corresponding to the $\mathrm{S}-\mathrm{O}-\mathrm{S}$ vibration verified the impossibility of the formation of S-O-S bridges and long sulphate chains in this glass network. Thus, the incorporation of sulphate ions mostly contributed to the terminal units into polyphosphate chains. Raman and NMR spectra also did not display any evidence for $\mathrm{ZnO}$ $\mathrm{P}_{2} \mathrm{O}_{5}-\mathrm{SO}_{3}-\mathrm{Na}_{2} \mathrm{O}$ network formation. This in turn confirmed that the incorporation of the sulphate ions indeed contributed to the network formation as isolated groups [11]. Lai et al [12] studied the structure of $x \mathrm{Na}_{2} \mathrm{SO}_{4}-(1-x)\left(0.4 \mathrm{Fe}_{2} \mathrm{O}_{3}\right.$ $-0.6 \mathrm{P}_{2} \mathrm{O}_{5}$ ) glass and showed the incorporation of sulphate into the glass matrix. Therefore, the available data on particular local structural features remain contradictory. Interaction between sulphate and phosphate ions provides a good environment for RE ions to exhibit high luminescence efficiency with minimal non-radiative losses in these glass systems [13].

The present study evaluates the structural and physical properties of magnesium zinc sulfophosphate glasses under varying concentrations of the samarium $\left(\mathrm{Sm}^{3+}\right)$ ion $(0.0,0.5$, $1.0,1.5$ and $2.0 \mathrm{~mol} \%)$. Five glass samples were prepared using melt quenching method and systematically characterized via X-ray diffraction, UV-Vis spectroscopy, Raman spectroscopy and FTIR spectroscopy. 


\section{Materials and methods}

Five glass samples were prepared by the conventional melt quenching method using $\mathrm{P}_{2} \mathrm{O}_{5}, \mathrm{MgO}, \mathrm{ZnSO}_{4} \cdot 7 \mathrm{H}_{2} \mathrm{O}$ and $\mathrm{Sm}_{2} \mathrm{O}_{3}$ as starting raw materials. In each case, about $22 \mathrm{~g}$ powder constituents were placed in a crucible and then heated in a high temperature furnace at $1100^{\circ} \mathrm{C}$ for $1 \mathrm{~h} 30 \mathrm{~min}$. The melt was then poured into a preheated steel mould and annealed at a temperature of $300^{\circ} \mathrm{C}$ for $3 \mathrm{~h}$ to remove residual internal strains that can cause glass embrittlement. The obtained samples were polished and cut into the desired size to get highly transparent surfaces for optical measurements. The compositions $(\mathrm{mol} \%)$ and labels of prepared glasses are listed in table 1.

The X-ray diffraction (XRD) measurements were performed on a Bruker D8 Advance diffractometer using $\mathrm{Cu} \mathrm{K} \alpha$ $=1.54 \AA$ operated at $40 \mathrm{kV}$ and $100 \mathrm{~mA}$. Glass density was determined via the Archimedes method (Precisa XT 220 A) with toluene $\left(\rho=0.8669 \mathrm{~g} \mathrm{~cm}^{-3}\right)$ as immersion liquid. Fourier transform infrared (FTIR) spectra in the wavenumber range of $400-4000 \mathrm{~cm}^{-1}$ were recorded using Perkin Elmer Paragon 500 FTIR spectrophotometer with resolution of $\pm 4.0 \mathrm{~cm}^{-1}$, where $\mathrm{KBr}$ pellet technique was employed. A confocal Jobin Yvon (Model HR800 UV) spectrophotometer was used to capture the Raman spectra in the wavenumber range of $100-2000 \mathrm{~cm}^{-1}$. The argon ion laser with peak power of $20 \mathrm{~mW}$ operating at $514.55 \mathrm{~nm}$ was used as the excitation source.

\section{Results and discussion}

\section{$3.1 \quad X$-ray diffraction}

Figure 1 displays the typical XRD pattern of sample PZSMSm1.0. The presence of a broad hump without any sharp crystalline peaks indicates the true amorphous nature of the prepared glass sample.

\subsection{Density and molar volume}

Glass density is determined to get information about the structural compactness, interstitial spaces and coordination number. Table 2 enlists the density $(\rho)$ and molar volume

Table 1. Chemical composition and codes of synthesized glass system.

\begin{tabular}{lllll}
\hline & \multicolumn{4}{c}{ Composition (mol\%) } \\
\cline { 2 - 5 } Glass codes & $\mathrm{P}_{2} \mathrm{O}_{5}$ & $\mathrm{ZnSO}_{4}$ & $\mathrm{MgO}$ & $\mathrm{Sm}_{2} \mathrm{O}_{3}$ \\
\hline PZSMSm0.0 & 60.0 & 20.0 & 20.0 & 0.0 \\
PZSMSm0.5 & 59.5 & 20.0 & 20.0 & 0.5 \\
PZSMSm1.0 & 59.0 & 20.0 & 20.0 & 1.0 \\
PZSMSm1.5 & 58.5 & 20.0 & 20.0 & 1.5 \\
PZSMSm2.0 & 58.0 & 20.0 & 20.0 & 2.0 \\
\hline
\end{tabular}

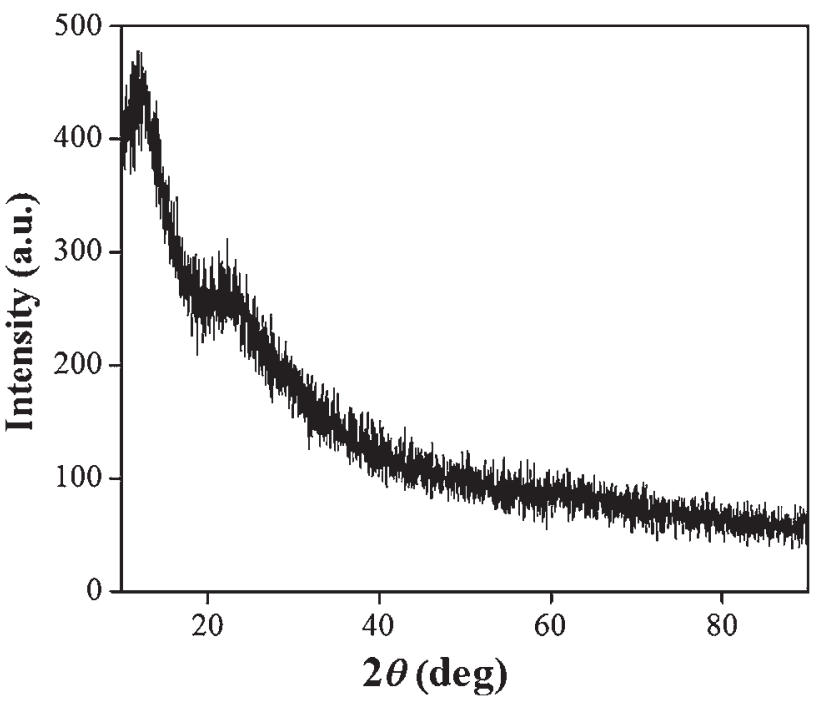

Figure 1. Typical XRD pattern of PZSMSm1.0 glass sample.

$\left(V_{\mathrm{m}}\right)$ of the prepared glasses. Figure 2 illustrates the $\mathrm{Sm}_{2} \mathrm{O}_{3}$ concentration-dependent variation of the glass density and molar volume of studied glasses. An increase in the density due to the inclusion of $\mathrm{Sm}_{2} \mathrm{O}_{3}$ is attributed to the substitution of lighter $\mathrm{P}_{2} \mathrm{O}_{5}\left(141.94 \mathrm{~g} \mathrm{~mol}^{-1}\right)$ groups by heavier $\mathrm{Sm}_{2} \mathrm{O}_{3}$ $\left(348.7 \mathrm{~g} \mathrm{~mol}^{-1}\right)[14,15]$. This higher density of glass indicates the enhancement of a degree of structural compactness [16]. The molar volume of glass samples is decreased with increasing $\mathrm{Sm}^{3+}$ concentration. It is due to the decrease in the inter-atomic spacing and increase in the stretching force constant [17]. The achieved higher compactness of the network structure is consistent with the other findings [18].

\subsection{Physical and optical properties}

The $\mathrm{Sm}^{3+}$ ions concentration $(N)$ is calculated using the equation (1):

$$
N=\frac{\text { Mol } \% \text { of dopant } \times \rho \times N_{\mathrm{A}}}{\text { Average molecular weight of glass }}
$$

where $N_{\mathrm{A}}$ is the Avogadro's number.

Physical features such as polaron radius $\left(r_{\mathrm{p}}\right)$, inter-nuclear distance $\left(r_{\mathrm{i}}\right)$ and field strength $(F)$ are calculated using the equations (2-4) [19]

$$
\begin{aligned}
& r_{\mathrm{p}}(\AA)=\frac{1}{2}\left(\frac{\pi}{6 N}\right)^{1 / 3} \\
& r_{\mathrm{i}}(\AA)=\left(\frac{1}{N}\right)^{1 / 3} \\
& F\left(\mathrm{~cm}^{2}\right)=\frac{Z}{r_{\mathrm{p}}^{2}}
\end{aligned}
$$


Table 2. Physical properties of synthesized glass samples.

\begin{tabular}{|c|c|c|c|c|c|}
\hline Physical properties & PZSMSm0.0 & PZSMSm0.5 & PZSMSm1.0 & PZSMSm1.5 & PZSMSm2.0 \\
\hline Density $\left(\mathrm{g} \mathrm{cm}^{-3}\right)( \pm 0.0317)$ & 2.6619 & 2.6860 & 2.7127 & 2.7244 & 2.7541 \\
\hline Molar volume $\left(\mathrm{cm}^{3}\right)( \pm 0.1370)$ & 56.6258 & 56.5024 & 56.3285 & 56.4653 & 56.2332 \\
\hline $\mathrm{Sm}^{3+}$ ions concentration $\left(\times 10^{20}\right.$ ion $\left.\mathrm{cm}^{-3}\right)( \pm 0.5990)$ & 0 & 0.5329 & 1.0691 & 1.5997 & 2.1418 \\
\hline Polaron radius of $\mathrm{Sm}^{3+}$ ions $(\AA)( \pm 1.5039)$ & 0 & 10.7073 & 8.4897 & 7.4224 & 6.7345 \\
\hline Inter-nuclear distance of $\mathrm{Sm}^{3+}$ ions $(\AA)( \pm 0.3732)$ & 0 & 26.5737 & 21.0699 & 18.4211 & 16.7138 \\
\hline Field strength of $\mathrm{Sm}^{3+}$ ions $\left(\times 10^{14} \mathrm{~cm}^{-2}\right)( \pm 1.4875)$ & 0 & 2.6167 & 4.1623 & 5.4454 & 6.6148 \\
\hline Di-electric constant $( \pm 0.0034)$ & 3.4213 & 3.3985 & 3.4194 & 3.4446 & 3.3987 \\
\hline Reflection loss $(\%)( \pm 0.0069)$ & 8.8903 & 8.7998 & 8.8828 & 8.9825 & 8.8006 \\
\hline Molar polarizability $\left(\times 10^{-24} \mathrm{~cm}^{3}\right)( \pm 0.0049)$ & 4.9572 & 4.9184 & 4.9288 & 4.9715 & 4.8952 \\
\hline Molar refraction $\left(\mathrm{cm}^{3} \mathrm{~mol}^{-1}\right)( \pm 0.0124)$ & 12.4981 & 12.4002 & 12.4267 & 12.5343 & 12.3418 \\
\hline
\end{tabular}

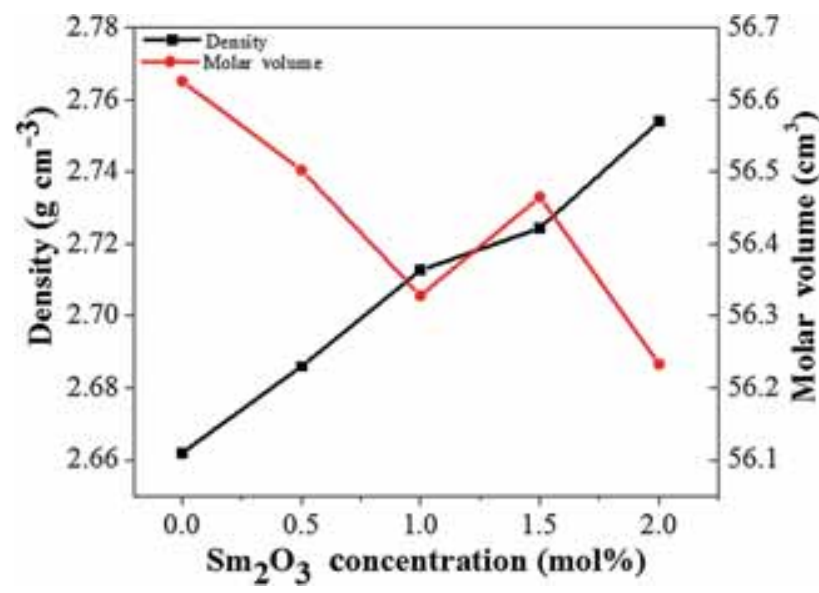

Figure 2. Variation of density and molar volume as a function of $\mathrm{Sm}_{2} \mathrm{O}_{3}$ concentration.

Both the polaron radius and inter-nuclear distance (enlisted in table 2) are found to decrease with the addition of $\mathrm{Sm}^{3+}$ ions into the glass matrix, which suggests that there is an increase in Sm-O bond strength producing stronger field strength around $\mathrm{Sm}^{3+}$ ions $(F)[20,21]$. It is worth mentioning to note that these results are in good agreement with the density results and confirms compactness of glass structure with the increase in $\mathrm{Sm}^{3+}$ ions.

3.3a Refractive index: The value of refractive index $(n)$ for different samples was obtained from the optical bandgap energies using Dimitrov and Sakka relation (equation 5) [22]:

$$
\frac{n^{2}-1}{n^{2}+2}=1-\sqrt{\frac{E_{\mathrm{opt}}}{20}}
$$

Table 3 enlists the results of $\mathrm{Sm}^{3+}$ ions concentrationdependent refractive index, which are in good agreement with literature values. However, these values for the studied glass system are higher than those of phosphate glasses [23,24] and close to the boro-tellurite glass systems [25]. Figure 3 depicts
Table 3. Comparison of refractive index of the synthesized (60.0 x) $\mathrm{P}_{2} \mathrm{O}_{5}-20.0 \mathrm{MgO}-20.0 \mathrm{ZnSO}_{4}-x \mathrm{Sm}_{2} \mathrm{O}_{3}(0.0 \leq x \leq 2.0 \mathrm{~mol} \%)$ glass system with other reported systems in the literature.

\begin{tabular}{lcc}
\hline RE concentration & $n$ & Reference \\
\hline$(60.0-x) \mathrm{P}_{2} \mathrm{O}_{5}-20.0 \mathrm{MgO}-20.0 \mathrm{ZnSO}_{4}-x \mathrm{Sm}_{2} \mathrm{O}_{3}$ & \\
0.0 & 1.8497 & Present work \\
0.5 & 1.8435 & Present work \\
1.0 & 1.8492 & Present work \\
1.5 & 1.8560 & Present work \\
2.0 & 1.8436 & Present work \\
$(59-x / 2) \mathrm{P}_{2} \mathrm{O}_{5}-15 \mathrm{~K}_{2} \mathrm{O}-(17-x / 2) \mathrm{MgO}_{-}-\mathrm{Al}_{2} \mathrm{O}_{3}-x \mathrm{Sm}_{2} \mathrm{O}_{3}$ \\
1.0 & 1.5130 & {$[23]$} \\
$41 \mathrm{P}_{2} \mathrm{O}_{5}-17 \mathrm{~K}_{2} \mathrm{O}-8 \mathrm{Al}_{2} \mathrm{O}_{3}-(24-x) \mathrm{ZnF}_{2}-10 \mathrm{LiF}_{-} x \mathrm{Sm}_{2} \mathrm{O}_{3}$ \\
1.0 & 1.5320 & {$[24]$} \\
$(36-x) \mathrm{B}_{2} \mathrm{O}_{3}-30 \mathrm{TeO}_{2}-19 \mathrm{ZnO}-15 \mathrm{Li}_{2} \mathrm{O}-x \mathrm{Sm}_{2} \mathrm{O}_{3}$ & \\
3.0 & 1.7360 & {$[25]$} \\
\end{tabular}

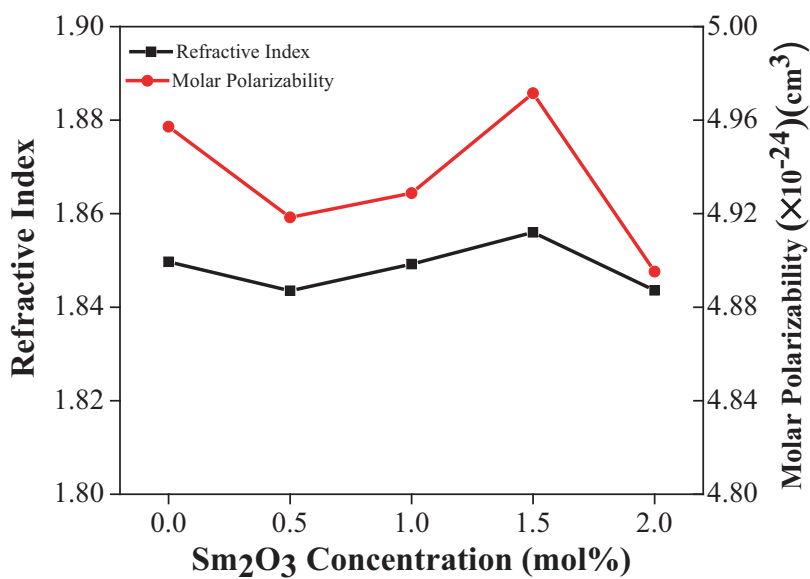

Figure 3. Variation of refractive index and molar polarizability as function of $\mathrm{Sm}_{2} \mathrm{O}_{3}$ concentration.

the variation of refractive index and molar polarizability of synthesized glass samples against $\mathrm{Sm}^{3+}$ ions concentration. Refractive index is first slightly decreased due to the introduction of $\mathrm{Sm}^{3+}$ ions in the host glass and then increased 
followed by a reduction. Refractive index becomes highest at $1.5 \mathrm{~mol} \%$ of $\mathrm{Sm}^{3+}$ ions. The decrease in refractive index is assigned to the lower ionic radii $(1.079 \AA)$ of $\mathrm{Sm}^{3+}$ and lack of polarization due to network structural changes. Conversely, the increased packing of $\mathrm{Sm}^{3+}$ ions into the host matrix has a direct effect on the increase of the refractive index.

The molar refraction $\left(R_{\mathrm{m}}, \mathrm{cm}^{3} \mathrm{~mol}^{-1}\right)$ is estimated using Lorentz-Lorenz equation (6) written as:

$$
R_{\mathrm{m}}=\frac{n^{2}-1}{n^{2}+2} V_{\mathrm{m}}
$$

Molar electronic polarizability is proportional to the molar refraction, which is related to the structure of the oxide glass. Molar polarizability $\left(\alpha_{\mathrm{m}}\right)$ is given by the equation (7):

$$
R_{\mathrm{m}}=4 \pi \alpha_{\mathrm{m}} N_{\mathrm{A}} / 3
$$

The di-electric constant $(\varepsilon)$, refraction loss $(R)$ are calculated using the equations ( 8 and 9 ):

$$
\begin{aligned}
\varepsilon & =n^{2} \\
R & =\left(\frac{n-1}{n+1}\right)^{2}
\end{aligned}
$$

3.3b Optical absorption: The study of absorption spectra in the UV region is regarded as an effective method to explore the optical bandgap in the amorphous systems. In optical transitions, interaction between the electromagnetic waves and the electrons in the valence band cause electrons to raise from fundamental gap to conduction band. Direct and indirect transitions are the optical transitions, which occur in amorphous and crystalline materials. The optical bandgap energy $\left(E_{\mathrm{opt}}\right)$ for both direct $\left(E_{\mathrm{opt}}^{\mathrm{dir}}\right)$ and indirect $\left(E_{\mathrm{opt}}^{\text {indir }}\right)$ transitions are calculated using the UV absorption edge of the UV-Vis-NIR spectra via Tauc's plot. The absorption coefficient $(\alpha(v))$ as a function of photon energy $(h v)$ is expressed in the equation (10) as [26]:

$$
\alpha(v)=B \frac{\left(h v-E_{\mathrm{opt}}\right)^{r}}{h v}
$$

where $B$ is a constant.

Figure 4 displays the Tauc's plot $\left((\alpha h v)^{1 / r} \sim h v\right)$, with $r=$ $1 / 2$ for direct and $r=2$ for indirect allowed transitions. The linear portion of the curves upon extrapolation at $(\alpha h v)^{2}=$ 0 and $(\alpha h v)^{1 / 2}=0$ yields direct (figure $4 \mathrm{a}$ ) and indirect (figure $4 b$ ) optical bandgap energy values.

As listed in table 4, the optical bandgap energy is varied nonlinearly with $\mathrm{Sm}_{2} \mathrm{O}_{3}$ contents. Figure 5 illustrates the $\mathrm{Sm}^{3+}$ ions concentration-dependent changes in the optical bandgap energy. Both the direct and indirect optical bandgap energy is first increased and then decreased with addition of $\mathrm{Sm}^{3+}$ ions up to $1.5 \mathrm{~mol} \%$ and increased at $2.0 \mathrm{~mol} \%$. This
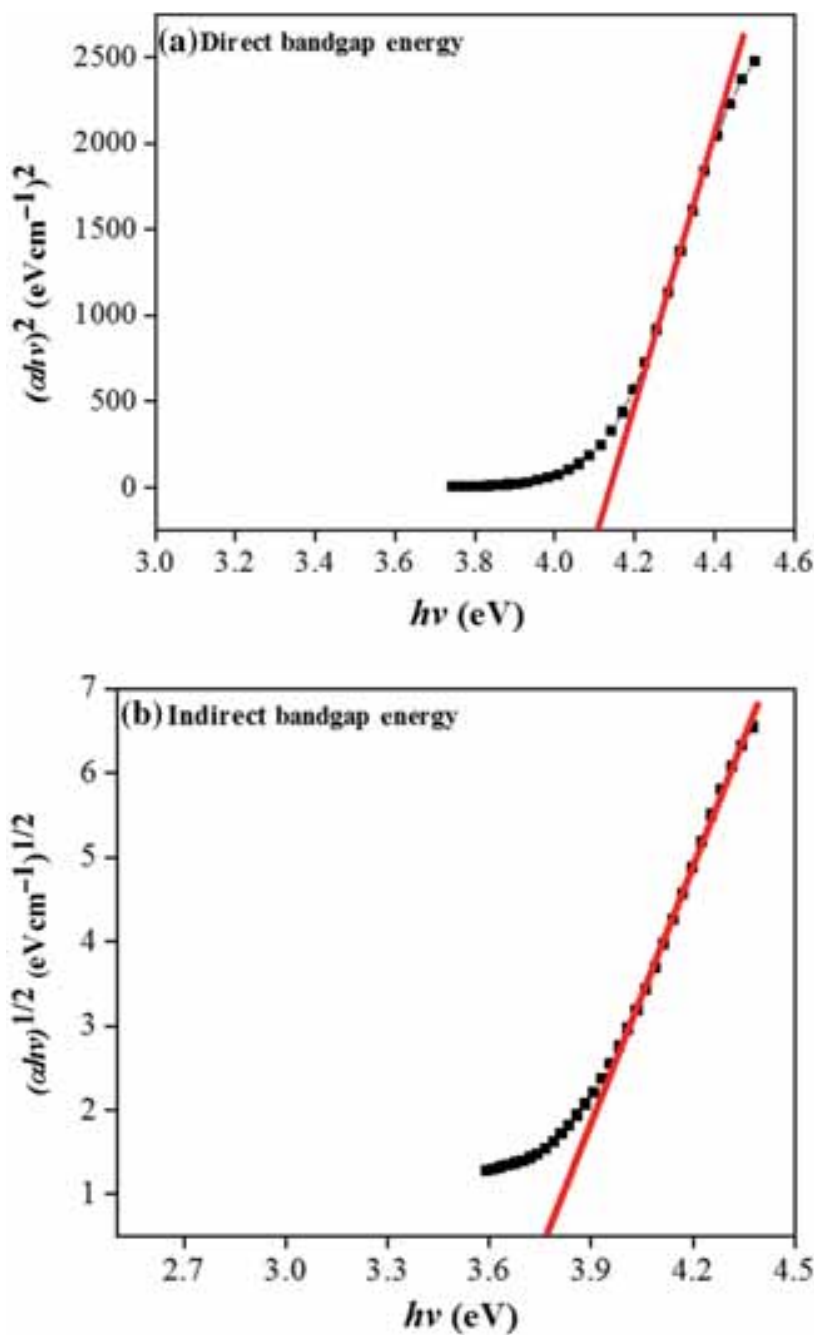

Figure 4. Typical Tauc's plot for PZSMSm0.5 glass (a) direct and (b) indirect transitions.

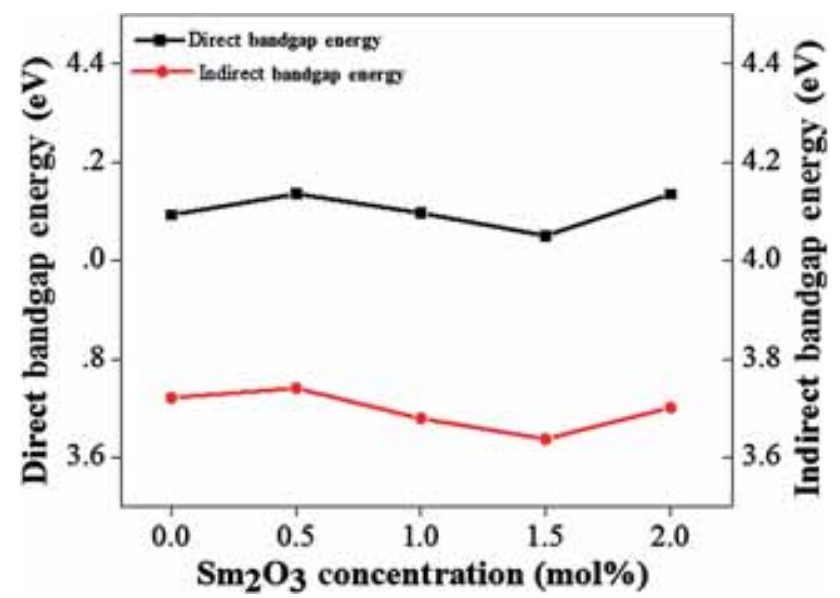

Figure 5. $\mathrm{Sm}_{2} \mathrm{O}_{3}$ concentration-dependent variations of direct and indirect optical bandgap energy for all samples. 
Table 4. Comparison of the optical bandgap and Urbach energy of the (60.0 $x) \mathrm{P}_{2} \mathrm{O}_{5}-20.0 \mathrm{MgO}-20.0 \mathrm{ZnSO}_{4}-x \mathrm{Sm}_{2} \mathrm{O}_{3}(0.0 \leq x \leq 2.0 \mathrm{~mol} \%)$ glass system with other findings.

\begin{tabular}{lccll}
\hline $\mathrm{Sm}^{3+}$ concentration & $E_{\mathrm{opt}}^{\mathrm{dir}}(\mathrm{eV})$ & $E_{\mathrm{opt}}^{\mathrm{indir}}(\mathrm{eV})$ & $\Delta E(\mathrm{eV})$ & Reference \\
\hline$(60.0-x) \mathrm{P}_{2} \mathrm{O}_{5}-20.0 \mathrm{MgO}-20.0 \mathrm{ZnSO}_{4}-x \mathrm{Sm}_{2} \mathrm{O}_{3}$ & & \\
0.0 & 4.0925 & 3.7214 & 0.1696 & Present work \\
0.5 & 4.1350 & 3.7409 & 0.1838 & Present work \\
1.0 & 4.0960 & 3.6793 & 0.2190 & Present work \\
1.5 & 4.0498 & 3.6374 & 0.2017 & Present work \\
2.0 & 4.1346 & 3.7013 & 0.2106 & Present work \\
$\mathrm{Mg}_{-} \mathrm{P}_{2} \mathrm{O}_{5}$ & & & & \\
$\overline{\mathrm{Zn}}-\mathrm{P}_{2} \mathrm{O}_{5}$ & 4.52 & 3.70 & 0.40 & {$[29]$} \\
$\overline{\mathrm{Ca}}-\mathrm{P}_{2} \mathrm{O}_{5}$ & & & & \\
- & - & 3.44 & 0.29 & {$[30]$} \\
\hline
\end{tabular}

reduction in the bandgap energy is attributed to the structural changes in the glass network and the formation of higher number of non-bridging oxygens (NBOs) [27]. Decrement in the optical bandgap is ascribed to the decrease in the average value of bond energy. Lower bonding energies of NBOs is responsible for the reduction of the optical bandgap energy. Therefore, electrons can easily transfer to the conduction band from the valence band. The generation of higher number of NBOs due to the rupture of oxygen bonding in the glass strongly influenced the absorption characteristics. Moreover, the position of absorption edge is greatly influenced by the oxygen bond strength in the glass formation network [27]. Consequently, incorporation of $\mathrm{Sm}^{3+}$ inside the glass host modified the oxygen bonding in glass network then the absorption characteristics has altered the formation of NBOs. The NBO bonds cause higher cations, refraction and polarizability, since these bonds have more ionic character and much lower band energies $[18,28]$.

These results are in good agreement with the other finding as summarized in table 4 .

3.3c Urbach energy: Urbach energy $(\Delta E)$ is used as a yardstick to measure the disorder in the amorphous system. Higher value of $\Delta E$ indicates greater tendency of the disorder system to convert weak bonds into defects. Urbach rule [32] for amorphous materials is given by the equation (11):

$$
\alpha(v)=\alpha_{0} \exp \left(\frac{h v}{\Delta E}\right)
$$

where $\alpha(v)$ is the absorption coefficient at a particular temperature in the optical region near the absorption edge and $\alpha_{0}$ is a constant called band tailing parameter. The extensions of the valence and conduction bands to the bandgap region cause the exponential behaviour of the band tail. Table 4 gives the $\Delta E$ values that are calculated from the Urbach's plots of

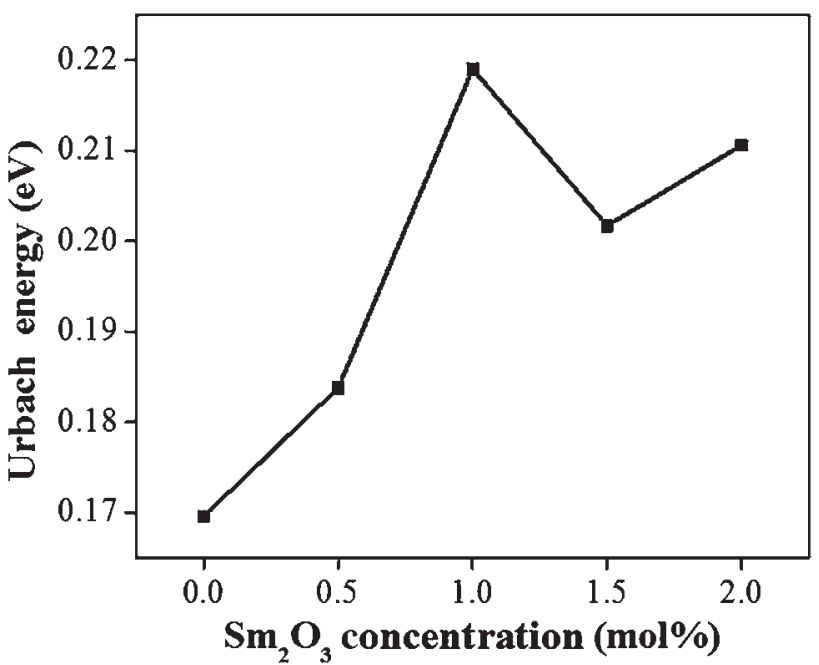

Figure 6. Variation of Urbach energy with $\mathrm{Sm}_{2} \mathrm{O}_{3}$ concentration.

$\ln (\alpha) v s .(h v)$ by taking the reciprocal of the slopes of the linear portion of the curves.

Figure 6 presents the variation of $\Delta E$ with $\mathrm{Sm}_{2} \mathrm{O}_{3}$ concentration, which increases by addition of $\mathrm{Sm}_{2} \mathrm{O}_{3}$ concentration up to $1.0 \mathrm{~mol} \%$ from $\sim 0.1696$ to $\sim 0.2190 \mathrm{eV}$. Urbach energy is known as a scale of disorder in the system and there is a trend to convert weak bonds into defects for materials with larger Urbach energy. It is obvious that $1.0 \mathrm{~mol} \% \mathrm{Sm}^{3+}$ doped PZSM glass shows further disorder in the present glass because it has the highest value of Urbach energy.

\subsection{FTIR spectra}

In phosphate glasses, three-dimensional glass networks are formed by $\mathrm{PO}_{4}$ tetrahedra [33] connected up to three of the four corners, where the doubly bonded oxygen atom remains 
as the fourth one. The phosphate tetrahedra can be described based on the number of bridging oxygen atoms [34-36]. A fully polymerized neutral unit of structure $\left(\right.$ denoted $\left.Q^{3}\right)$ and a structure based on chains and rings $\left(\mathrm{Q}^{2}\right)$ with negative charge forms the network. In addition, there exists two tetrahedral units connected by a corner $\left(\mathrm{Q}^{1}\right)$ and isolated tetrahedra $\left(\mathrm{Q}^{0}\right)$ with charges -2 and -3 , respectively. The $\mathrm{O} / \mathrm{P}$ ratio of the glass composition strongly determines the structure of the phosphate glasses [37]. The incorporation of metal ion in these phosphate glasses results in breakdown of the $\mathrm{P}-\mathrm{O}-$ $\mathrm{P}$ bonds and formation of $\mathrm{P}-\mathrm{O}-\mathrm{M}(\mathrm{M}$ : metal) bonds. The dominance of a particular $\mathrm{Q}$ unit depends on the nature and concentration of the cations present in the glass. The strong glass forming oxide of $\mathrm{P}_{2} \mathrm{O}_{5}$ contributes to the glass network with $\mathrm{PO}_{4}$ structural clusters. These $\mathrm{PO}_{4}$ tetrahedra are interconnected together with covalent bonding to form chains or rings. Both the nature of the modifier ions and $\mathrm{MO} / \mathrm{P}_{2} \mathrm{O}_{5}$ ratio largely alters the chains or rings of phosphate groups. Hence, shortened chains contain three unshared oxygen corners to produce phosphate tetrahedra structure. These tetrahedra are expressed as $\left[\mathrm{POO}_{2 / 2} \mathrm{O}\right]^{-}$and $\left[\mathrm{POO}_{1 / 2} \mathrm{O}_{2}\right]^{2-}$ with two and one bridging oxygen, respectively. The bonding configuration of two bridging oxygen phosphate groups is represented as:

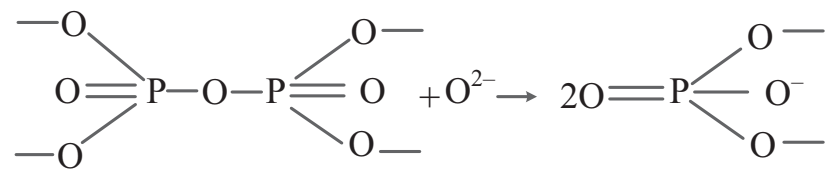

In the presence of the oxide modifier it undergoes a chemical reaction given by the equation (12):

$$
2\left[\mathrm{POO}_{3 / 2}\right]^{0}+\mathrm{MgO} \rightarrow 2\left[\mathrm{POO}_{2 / 2} \mathrm{O}\right]^{-}+\mathrm{Mg}^{2+}
$$

Likewise, the bonding configuration of the phosphate group with one bridging oxygen atom is represented as:<smiles>COP(=O)(OC)OP(=O)(OC)OC</smiles>

In the presence of the oxide modifier it undergoes a chemical reaction given by the equation (13):

$$
2\left[\mathrm{POO}_{2 / 2} \mathrm{O}\right]^{-}+\mathrm{MgO} \rightarrow 2\left[\mathrm{POO}_{1 / 2} \mathrm{O}_{2}\right]^{2-}+\mathrm{Mg}^{2+}
$$

When the phosphate network involves $\left[\mathrm{POO}_{2 / 2} \mathrm{O}\right]^{-}$and $\left[\mathrm{POO}_{1 / 2} \mathrm{O}_{2}\right]^{2-}$ structural groups then $\mathrm{ZnSO}_{4}$ and $\mathrm{P}_{2} \mathrm{O}_{5}$ can form the glass [7]. Moreover, when both sulfate and $\left[\mathrm{POO}_{2 / 2} \mathrm{O}\right]^{-}$ions are present the $\mathrm{SPO}_{7}^{3-}$ (dithiophosphate) species are readily formed in the glass matrix. It is worth noting that the atomic arrangement at short and intermediate range in the glass network being the most significant factor decides the emission features of the glass. The symmetry

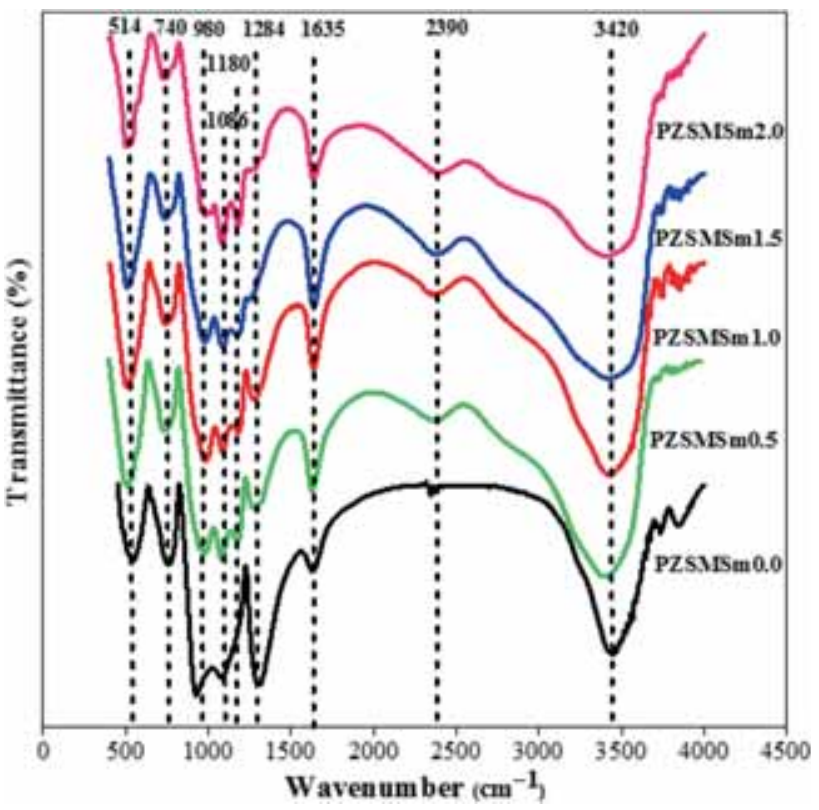

Figure 7. FTIR spectra of studied glass systems.

and/or covalency of the glass at the REIs are very different when various modifiers are incorporated between the longchain molecules in the vicinity of REIs in the S-O-P network. Besides, the variations in the concentration of different structural units of phosphate, sulfate ions and linkages between them also change the crystal field around the lanthanide ions in the glass network.

Figure 7 displays FTIR spectra of synthesized glasses in the wavenumber range of $400-4000 \mathrm{~cm}^{-1}$. The IR spectrum comprised of several bands that appeared around 514, 740, 980, 1086, 1180, 1284, 1635, 2390 and $3420 \mathrm{~cm}^{-1}$, which are assigned to different bonding vibrations. The FTIR band position and their assignment for the proposed glass systems are summarized as follows:

(i) The IR bands recorded at $\sim 514 \mathrm{~cm}^{-1}$ is assigned to $\mathrm{P}-\mathrm{O}$ bonds vibration $[38,39]$.

(ii) The band observed at $\sim 740 \mathrm{~cm}^{-1}$ is originated from the symmetric stretching vibration of $\mathrm{P}-\mathrm{O}-\mathrm{P}$ linkages [40-42].

(iii) The band observed at $\sim 980 \mathrm{~cm}^{-1}$ is assigned to the asymmetric stretching vibration of $\mathrm{P}-\mathrm{O}-\mathrm{P}$ linkages $[38,43,44]$.

(iv) The band at $\sim 1086 \mathrm{~cm}^{-1}$ is allocated to the symmetric stretching vibration of $\mathrm{PO}_{2}$ [45].

(v) There is only one mode of the $\mathrm{SO}_{4}^{2-}$ at $\sim 1180 \mathrm{~cm}^{-1}$ which is due to asymmetric modes of $\mathrm{SO}_{4}^{2-}$ groups or symmetric stretching vibration of $\mathrm{PO}_{2}[13,46,47]$. This mode is presented in $(60.0-x) \mathrm{P}_{2} \mathrm{O}_{5}-20.0 \mathrm{MgO}-$ $20.0 \mathrm{ZnSO}_{4}-x \mathrm{Sm}_{2} \mathrm{O}_{3}(0.0 \leq x \leq 2.0 \mathrm{~mol} \%)$ samples, except in undoped magnesium zinc sulfophosphate glass. 
(vi) The band at $\sim 1284 \mathrm{~cm}^{-1}$ is assigned to antisymmetrical vibrations of $\mathrm{PO}_{2}$ groups $/ \mathrm{P}=\mathrm{O}$ stretching vibrations [13,46,47].

(vii) The band at $\sim 1635 \mathrm{~cm}^{-1}$ is attributed to the bending vibration of $\mathrm{H}-\mathrm{O}-\mathrm{H}$ bonds because of the air moisture during the preparation of $\mathrm{KBr}$ pellets for infrared measurements $[44,48]$.

(viii) A band at $\sim 2390 \mathrm{~cm}^{-1}$ is due to $\mathrm{O}-\mathrm{H}$ bond stretching vibrations [48-50].

(ix) The band at $\sim 3420 \mathrm{~cm}^{-1}$ is assigned to the $\mathrm{O}-\mathrm{H}$ stretching of hydrated water $[43,48,51,52]$.

As can be seen in figure 7, a new feature appeared at around $1180 \mathrm{~cm}^{-1}$ in the spectra of Sm-doped glass samples. This band is attributed to the asymmetric modes of $\mathrm{SO}_{4}^{2-}$ groups or symmetric stretching of $\mathrm{PO}_{2}$. In addition, the intensity of the band at $\sim 1284 \mathrm{~cm}^{-1}$ decreases with the addition of $\mathrm{Sm}_{2} \mathrm{O}_{3}$ ions concentration, which shows that the addition of $\mathrm{Sm}_{2} \mathrm{O}_{3}$ to the magnesium zinc sulfophosphate glass network result in the formation of the NBO bonds as a consequence of more breakdowns of the $\mathrm{P}=\mathrm{O}$. The intensity of the band occurred at $1635 \mathrm{~cm}^{-1}$ is found to increase with addition of $\mathrm{Sm}_{2} \mathrm{O}_{3}$ ions concentration. Since the hygroscopic character of these glasses is increased by adding $\mathrm{Sm}^{3+}$ ions concentration, the stability of the glasses is decreased.

\subsection{Raman spectra}

Figure 8 illustrates the typical Raman spectrum of $\mathrm{Sm}^{3+}$ doped PZSM glasses, which comprised of several peaks occurred at 333, 465, 524, 694, 750, 901, 993, 1066, $1175,1203,1291$ and $1367 \mathrm{~cm}^{-1}$. In addition, four modes $\left(v_{1}, v_{2}, v_{3}\right.$ and $\left.v_{4}\right)$ vibrational modes of $\mathrm{SO}_{4}$ groups are also detected [53]. Some of the vibrations of $\mathrm{SO}_{4}$ and phosphate groups are overlapped, which is due to the possible

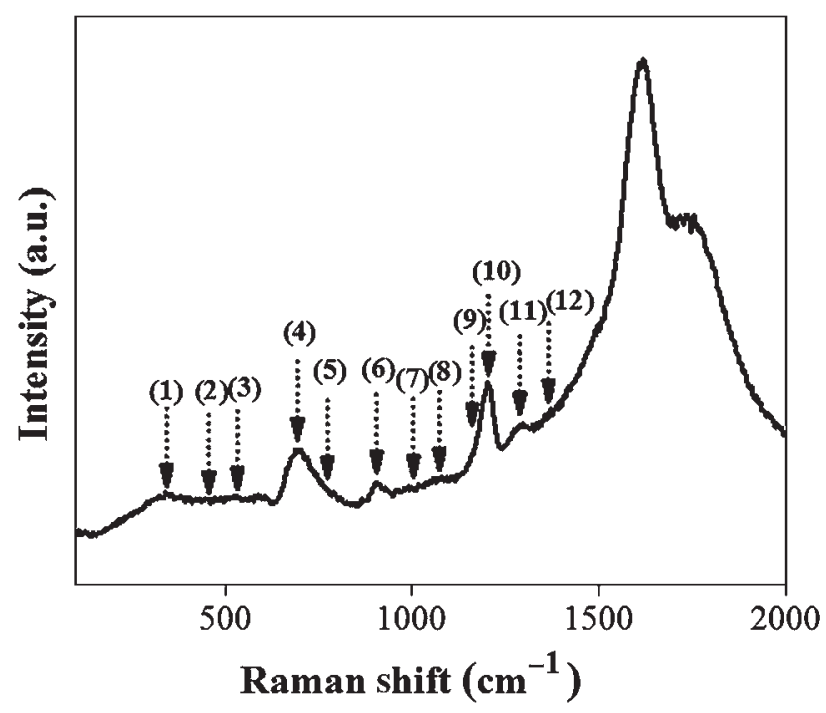

Figure 8. Raman spectra of PZSMSm1.0 glass. inter-cluster covalence-ionic interactions between these groups. The details of various band positions and their assignments are enlisted as follows:

(i) The bands at $\sim 333$ and $\sim 524 \mathrm{~cm}^{-1}$ are allocated to the bending mode of phosphate polyhedral with zinc as modifier and zinc-phosphate network or zinc in tetrahedral site, respectively [54].

(ii) The band at $\sim 465 \mathrm{~cm}^{-1}$ is related to the symmetric $\mathrm{O}-\mathrm{S}-\mathrm{O}$ bending modes $v_{2}-\mathrm{SO}_{4}[13,53]$.

(iii) The bands at $\sim 694$ and $\sim 750 \mathrm{~cm}^{-1}$ are assigned to symmetric vibrations of the $\mathrm{P}-\mathrm{O}-\mathrm{P}$ linkages [55]. Furthermore, the band at $\sim 694 \mathrm{~cm}^{-1}$ attributed to asymmetric $\mathrm{O}-\mathrm{S}-\mathrm{O}$ bend modes $v_{4}-\mathrm{SO}_{4}[11,53,56]$.

(iv) The band at $\sim 901 \mathrm{~cm}^{-1}$ is related to asymmetric stretching vibration of $\mathrm{P}-\mathrm{O}-\mathrm{P}$ group in metaphosphate [11].

(v) The band at $\sim 993 \mathrm{~cm}^{-1}$ is related to the $\mathrm{S}-\mathrm{O}$ symmetric stretching vibrations $v_{1}-\mathrm{SO}_{4}[11,53,57]$.

(vi) The band at $\sim 1066 \mathrm{~cm}^{-1}$ is allocated to $\mathrm{P}-\mathrm{O}$ symmetric stretching on $\mathrm{Q}^{2}[11,56]$.

(vii) The band at $\sim 1175 \mathrm{~cm}^{-1}$ is related to the asymmetric $\mathrm{S}-\mathrm{O}$ stretching mode vibrations $\left(v_{3}-\mathrm{SO}_{4}\right)$ and symmetric stretching of $\mathrm{NBO}$ on $\mathrm{Q}^{2}[13,53]$.

(viii) The bands at $\sim 1203$ and $\sim 1291 \mathrm{~cm}^{-1}$ are assigned to the symmetric and asymmetric $\mathrm{PO}_{2}$ stretching mode vibrations in $\mathrm{Q}^{2}$ species, respectively $[11,13]$.

(ix) The band at $\sim 1367 \mathrm{~cm}^{-1}$ is assigned to symmetric stretching vibration of $\mathrm{P}=\mathrm{O}$ bonds [13].

Figure 8 contains sharp bands due to the symmetric vibrations of the $\mathrm{P}-\mathrm{O}-\mathrm{P}$ linkages and symmetric $\mathrm{PO}_{2}$ stretching mode vibrations in $\mathrm{Q}^{2}$ near 694 and $1203 \mathrm{~cm}^{-1}$, respectively. Finally, there is no evidence in Raman spectra to confirm the incorporation of the $\mathrm{SO}_{4}^{2-}$ ions to the network formation; so, $\mathrm{SO}_{4}^{2-}$ ions contribute in the form of isolated groups. This behaviour of sulfate ions have been reported in previous studies [11].

\section{Conclusion}

The structural and physical properties of $\mathrm{Sm}^{3+}$ doped magnesium zinc sulfophosphate glasses were determined. The observed increase in the glass density with the increase of $\mathrm{Sm}^{3+}$ contents was attributed to the substitution of a lighter molecular weight agent with a heavier one in the glass network. Direct and indirect optical bandgap energies were decreased with increasing $\mathrm{Sm}^{3+}$ ion content up to 1.5 mol\% and then increased. This nonlinearity trend in the optical bandgap energy was ascribed to the formation of a greater number of NBOs. Furthermore, four vibrational modes of $\mathrm{SO}_{4}$ groups were detected in the Raman spectra. 


\section{Acknowledgements}

We are grateful to UTM and Ministry of Education for the financial support through Vote 12H42, 13H50 (GUP) and 4F424 (FRGS).

\section{References}

[1] Suratwala T, Steele R, Wilke G, Campbell J and Takeuchi K 2000 J. Non-Cryst. Solids 263213

[2] Praveena R, Venkatramu V, Babu P and Jayasankar C 2008 Physica B: Condens. Matter $\mathbf{4 0 3} 3527$

[3] Da N, Krolikowski S, Nielsen K H, Kaschta J and Wondraczek L 2010 J. Am. Ceram. Soc. 932171

[4] Mamoshin V, Arkhipov V, Buler P and Ivanova L 1987 Fiz. Khim. Stekla 13510

[5] Mamoshin V 1996 Glass Ceram. 53166

[6] Arkhipov V, Ivanova L, Mamoshin V, Buler P, Lushchai O and Galnykina L 1986 J. Appl. Spectros. 45976

[7] Ganguli M, Bhat M H and Rao K J 1999 Solid State Ion. 122 23

[8] Nepomiluev A, Pletnev R, Lapina O, Kozlova S and Bamburov V 2002 Glass Phys. Chem. 281

[9] Sokolov I, Valova N, Tarlakov Y P and Pronkin A 2003 Glass Phys. Chem. 29548

[10] Sokolov I, Murin I, Kriyt V and Pronkin A 2011 Glass Phys. Chem. 37351

[11] Da N, Grassmé O, Nielsen K H, Peters G and Wondraczek L 2011 J. Non-Cryst. Solids 3572202

[12] Lai Y, Liang X, Yang S, Wang J and Zhang B 2012 J. Mol. Struct. 1013134

[13] Rao P R, Pavić L, Moguš-Milanković A, Kumar V R, Kityk I and Veeraiah N 2012 J. Non-Cryst. Solids 3583255

[14] Sastry S S and Rao B R V 2014 Physica B: Condens. Matter 434159

[15] Im S H, Na Y H, Kim N J, Kim D H, Hwang C W and Ryu B K 2010 Thin Solid Films 518 e46

[16] Halimah M, Daud W, Sidek H, Zaidan A and Zainal A 2010 Mater. Sci. Pol. 28173

[17] Bingham P, Hand R, Hannant O, Forder S and Kilcoyne S H 2009 J. Non-Cryst. Solids 3551526

[18] Sidek H, Rosmawati S, Talib Z, Halimah M and Daud W 2009 Am. J. Appl. Sci. 61489

[19] Shelby J E and Ruller J 1987 Phys. Chem. Glasses 28262

[20] Thomas S, George R, Nayab Rasool S, Rathaiah M, Venkatramu V, Joseph C et al 2013 Opt. Mater. 36242

[21] Dousti M R, Ghoshal S, Amjad R J, Sahar M, Nawaz F and Arifin R 2013 Opt. Commun. 300204

[22] Dimitrov V and Sakka S 1996 J. Appl. Phys. 791736

[23] Rao C S and Jayasankar C 2013 Opt. Commun. 286204

[24] Lim K-S, Vijaya N, Kesavulu C and Jayasankar C 2013 opt. Mater. 351557
[25] Selvaraju K and Marimuthu K 2013 J. Alloys Compd. 553273

[26] Davis E and Mott N 1970 Philos. Mag. 220903

[27] Nelson C, Furukawa T and White W B 1983 Mater. Res. Bull. 18959

[28] El-Mallawany R A 2011 Tellurite glasses handbook: physical properties and data (CRC press)

[29] Al-Ani S and Higazy A A 1991 J. Mater. Sci. 263670

[30] Khor S, Talib Z and Yunus W M 2012 Ceram. Int. 38935

[31] Talib Z A, Daud W, Tarmizi E, Sidek H and Yunus W 2008 J. Phys. Chem. Solids 691969

[32] Urbach F 1953 Phys. Rev. 921324

[33] Hoppe U 1996 J. Non-Cryst. Solids 195138

[34] Brow R K 2000 J. Non-Cryst. Solids 2631

[35] Moustafa Y and El-Egili K 1998 J. Non-Cryst. Solids 240144

[36] Burling L D 2006 Novel phosphate glasses for bone regeneration applications University of Nottingham

[37] Šantić A, Moguš-Milanković A, Furić K, Bermanec V, Kim C and Day D E 2007J. Non-Cryst. Solids 3531070

[38] Rasool S N, Moorthy L R and Jayasankar C 2013 Opt. Commun. 311156

[39] Reis S, Faria D, Martinelli J, Pontuschka W, Day D and Partiti C 2002 J. Non-Cryst. Solids 304188

[40] Kim C-W, Ray C, Zhu D, Day DE, Gombert D, Aloy A et al 2003 J. Nucl. Mater. 322152

[41] Kim C-W and Day D E 2003 J. Non-Cryst. Solids 33120

[42] Ardelean I, Rusu D, Andronache C and Ciobotă V 2007 Mater. Lett. 613301

[43] Pascuta P, Borodi G, Popa A, Dan V and Culea E 2010 Mater. Chem. Phys. 123767

[44] Qian B, Liang X, Yang S, He S and Gao L 2012 J. Mol. Struct. 102731

[45] Meyer K 1997 J. Non-Cryst. Solids 209227

[46] Lai Y, Liang X, Yang S, Wang J, Cao L and Dai B $2011 \mathrm{~J} . \mathrm{Mol}$. Struct. 99284

[47] Kumar A R, Rao C S, Krishna G M, Kumar V R and Veeraiah N 2012 J. Mol. Struct. 101639

[48] Tsai P and Greenblatt M 1988 J. Non-Cryst. Solids 103101

[49] Rudramadevi Band Buddhudu S 2008 Indian J. Pure Appl. Phys. 46825

[50] Babu Y C R, Naik P S R, Kumar K.V, Prasad S and Kumar A S 2012 Physica B: Condens. Matter 407705

[51] ElBatal F H, Ouis M A, Morsi R M and Marzouk S Y $2010 \mathrm{~J}$. Non-Cryst. Solids 35646

[52] Karthikeyan B and Mohan S 2003 Physica B: Condens. Matter 334298

[53] Hapanowicz R and Condrate Sr R 1996 J. Solid State Chem. 123183

[54] Brow R K, Tallant D R, Myers S T and Phifer C C 1995 J. Non-Cryst. Solids 19145

[55] Brow R K, Tallant D R, Hudgens J J, Martin S W and Irwin A D 1994 J. Non-Cryst. Solids 177221

[56] Massera J, Bourhis K, Petit L, Couzi M, Hupa L, Hupa M et al 2013 J. Phys. Chem. Solids 74121

[57] Karakassides M, Saranti A and Koutselas I 2004 J. Non-Cryst. Solids 34769 